\title{
Activities of N-Acetylgalactosamine-6-Sulfate Sulfatase in Liver from Two Sisters with Morquio Syndrome
}

\author{
Ryoji Minami, Katsuyuki Abo, Tooru Kudoh, Satosi \\ Tsugawa, * Kazuhiko Oyanagi and Tooru Nakao \\ Department of Pediatrics, Sapporo Medical College, Sapporo \\ 060, and *Otaru National Sanatorium, Otaru 047
}

\begin{abstract}
Minami, R., Abo, K., Kudoh, T., Tsugawa, S., Oxanagi, K. and Nakao, T. Activities of $N$-Acetylgalactosamine-6-Sulfate Sulfatase in Liver from Two Sisters with Morquio Syndrome. Tohoku J. exp. Med., 1980, 131 (1), 53-57 A 6-sulfated tetrasaccharide obtained by digesting chondroitin-6-sulfate with testicular hyaluronidase was used as a substrate for the determination of $\mathrm{N}$ acetylgalactosamine-6-sulfate sulfatase activity. The activity was not detected in liver obtained from the elder sister with clinically classic Morquio syndrome and $4.7 \%$ of the control in liver from the younger sister with the same disease.

$\mathrm{N}$-acetylgalactosamine-6-sulfate sulfatase; 6-sulfated tetrasaccharide; Morquio syndrome
\end{abstract}

Morquio syndrome (mucopolysaccharidosis IV) is an inherited disorder of mucopolysaccharide metabolism characterized by marked skeletal deformities, corneal clouding, normal intellect and excessive urinary excretion of keratan sulfate (KS). In 1974 Matalon et al. found that hexosamine-6-sulfate sulfatase activity was deficient in extracts of fibroblasts from Morquio syndrome. Singh et al. (1976) suggested that the defective enzyme was an $\mathrm{N}$-acetylgalactosamine-6sulfate sulfatase, using a 6-sulfated tetrasaccharide prepared from chondroitin-6sulfate (C-6-S) as a substrate. Recently, Di Ferrante et al. (1978) demonstrated that two forms of 6-sulfate sulfatases exist. One is a 6-sulfatase specific for substrates with the galactose configuration ( $\mathrm{N}$-acetylgalactosamine-6-sulfate and galactose-6-sulfate), the deficiency of which causes inability to degrade $\mathrm{KS}$ and C-6-S. The other enzyme is specific for substrates with the glucose configuration ( $\mathrm{N}$-acetylglucosamine-6-sulfate), the deficiency of which is responsible for inadequate degradation of KS and heparan sulfate (HS). A few papers, moreover, demonstrated that classic Morquio syndrome is caused by a deficiency of the $\mathrm{N}$-acetylgalactosamine-6-sulfate sulfatase (Di Ferrante et al. 1978; Ginsberg et al. 1978; Horwitz and Dorfman 1978).

In this paper, using a 6-sulfated tetrasaccharide obtained by digesting C-6-S with testicular hyaluronidase as a substrate, activities of $\mathrm{N}$-acetylgalactosamine-6sulfate sulfatase in liver obtained from two sisters with clinically classic Morquio syndrome are reported.

Received for publication, April 13, 1979. 


\section{Materials and Methods}

Patients. The liver specimens were obtained from four control individuals and two sisters with classic Morquio syndrome (18-year-old and 14-year-old). Tissues used as control were obtained postmortem from patients of similar ages with no apparent neurological disease. The two sisters with classic Morquio syndrome were diagnosed by clinical findings and chemical analysis (excessive urinary excretion of KS and the accumulation of $\mathrm{KS}$ in liver) as reported in previous papers (Orii et al. 1973; Minami et al. 1979). All the specimens were obtained at autopsy and stored at $-70^{\circ} \mathrm{C}$ for $1-2$ years until analysis.

Preparation of a substrate for $N$-acetylgalactosamine-6-sulfate sulfatase. Substrate was prepared by modified methods of Singh et al. (1976), and Glössl and Kresse (1978). $500 \mathrm{mg}$ of C-6.S (a galactosamine-6-sulfate/galactosamine-4-sulfate molar ratio of $90 / 10$, Seikagaku Kogyo Co.) was dissolved in $25 \mathrm{ml}$ of $0.1 \mathrm{M}$ sodium acetate buffer, pH 5.0 , containing $0.15 \mathrm{M} \mathrm{NaCl}$ and $0.02 \% \mathrm{NaN}_{3}$, and digested with $140 \mathrm{mg}$ of bovine testicular hyaluronidase (740 NF units/mg, type IV. Sigma) for $45 \mathrm{hr}$ at $37^{\circ} \mathrm{C}$. Enzyme action was stopped by addition of $75 \mathrm{ml}$ ethanol and centrifuged. The supernatant was collected and the undigested C-6-S was washed with ethanol. The undigested C-6-S was dissolved in $25 \mathrm{ml}$ of sodium acetate buffer and digested with hyaluronidase as described above. These procedures were repeated three times. The ethanol supernatant fractions were combined and concentrated with an evaporator. The concentrated degraded C-6-S was applied on Sephadex G-25 column $(190 \times 2 \mathrm{~cm})$ and eluted with $0.2 \mathrm{M} \mathrm{NaCl}$. Fractions $(5 \mathrm{ml})$ were collected at a flow rate of $25 \mathrm{ml} / \mathrm{hr}$. The column was calibrated with various carbohydrates of known molecular weights. Uronic acid-containing fractions corresponding to the elution position of a tetrasaccharide were pooled, concentrated and desalted on a Sephadex G-25 column $(90 \times 3.5 \mathrm{~cm})$. The desalted material was brought to dryness with an evaporator, dissolved in water and stored frozen until used.

Enzyme preparation. Enzyme source was prepared by the method of Singh et al. (1976). Liver tissues were homogenized with $1.2 \mathrm{ml} / \mathrm{g}$ wet weight of $0.15 \mathrm{M} \mathrm{NaCl}$ and centrifuged for $30 \mathrm{~min}$ at $600 \times \mathrm{g}$. The above procedures were carried out at $0^{\circ} \mathrm{C}$. The supernatant was dialyzed for $24 \mathrm{hr}$ at $4^{\circ} \mathrm{C}$ against $0.15 \mathrm{M} \mathrm{NaCl}$. The retained part was centrifuged at $20,000 \times \mathrm{g}$ for $30 \mathrm{~min}$ at $0^{\circ} \mathrm{C}$ and the supernatant was used as an enzyme source.

Assay of $N$-acetylgalactosamine-6-sulfate sulfatase. The reaction mixture consisted of $0.3 \mathrm{ml}$ of water containing $0.31 \mu$ mole of $\mathrm{NaN}_{3}, 0.15 \mathrm{ml}$ of $0.6 \mathrm{M}$ Tris-acetate buffer ( $\mathrm{pH}$ $4.5), 0.1 \mathrm{ml}$ of substrate $(20 \mathrm{mM}$ aqueous solution as uronic acid) and $0.2 \mathrm{ml}$ of enzyme source $\left(4.0-8.0 \mathrm{mg}\right.$ ). After incubation at $37^{\circ} \mathrm{C}$ for $18 \mathrm{hr}$, the released inorganic sulfate was measured as follows: To each tube was added $1.6 \mathrm{ml}$ of $4 \%$ trichloroacetic acid and centrifuged at $680 \times \mathrm{g}$ for $25 \mathrm{~min}$. To $1.4 \mathrm{ml}$ of each supernatant was added $0.5 \mathrm{ml}$ of gelatin- $\mathrm{BaCl}_{2}$ reagent. After $15 \mathrm{~min}$ at room temperature, the turbidity produced was measured at $360 \mathrm{~nm}$ (Dodgson and Price 1962; Singh et al. 1976).

Other methods. $\beta$-D-Galactosidase and $\mathrm{N}$-acetyl- $\beta$-D-glucosaminidase were assayed as previously described (Orii et al. 1976), using 4-methylumbelliferyl- $\beta$-D-galactopyranoside and 4-methylumbelliferyl-2-acetoamido-deoxy- $\beta$-D-glucopyranoside (Koch-Light), respectively. Uronic acid was determined by the Carbazole reaction (Dische 1974), hexosamine by the method of Svennerholm (1956), total sulfate by the method of Dodgson and Price (1962) and protein by the method of Lowry et al. (1951).

\section{Results and Discussion}

The C-6-S used for the preparation of the substrate had a uronic acid/hexosamine/total sulfate molar ratio of 1.00:0.90: 0.64. When the C-6-S was chromatographed on a Sephadex G-25 column, it was eluted as a sharp peak. The hyaluronidase-degraded-C-6-S was eluted as a broad peak (Fig. 1). The material 
corresponding to the elution position of a tetrasaccharide appeared to be essentially a 6 -sulfated tetrasaccharide, because the material had a uronic acid/hexosamine/ total sulfate molar ratio of 1.00:1.25:0.95 and when digested with $\beta$-glucuronidase, free uronic acid produced was equal to about $50 \%$ of the uronic acid of the material. It, moreover, was justified by other papers (Singh et al. 1976; Glössl and Kresse 1978 ) that the 4 -sulfated tetrasaccharide contaminated in the 6 -sulfated tetrasaccharide did not show any significant contribution to the amount of inorganic sulfate released on the determination of $\mathrm{N}$-acetylgalactosamine-6-sulfate sulfatase.

The $\mathrm{pH}$ activity curve (Fig. 2) showed that $\mathrm{N}$-acetylgalactosamine-6-sulfate sulfatase activity using 6 -sulfated tetrasaccharide had a $\mathrm{pH}$ optimum at 4.5. The time course of the reaction was linear for up to $24 \mathrm{hr}$ and the amount of the enzyme concentration was proportional up to $15 \mathrm{mg}$ of protein.

Although there are reports (Singh et al. 1976; Di Ferrante et al. 1978; Glössl and Kresse 1978; Ginsberg et al. 1978; Horwitz and Dorfman 1978) concerning Nacetylgalactosamine-6-sulfate sulfatase activities in leukocytes and cultured fibroblasts from Morquio syndrome, the activity in the liver was only reported by Koto et al. (1978).

Using the 6-sulfated tetrasaccharide as substrate, average activity of the $\mathrm{N}$ acetylgalactosamine-6-sulfate sulfatase in liver from control individuals was 46.9 nmoles inorganic sulfate $/ \mathrm{mg}$ protein $/ 18 \mathrm{hr}$. On the other hand, the activity was

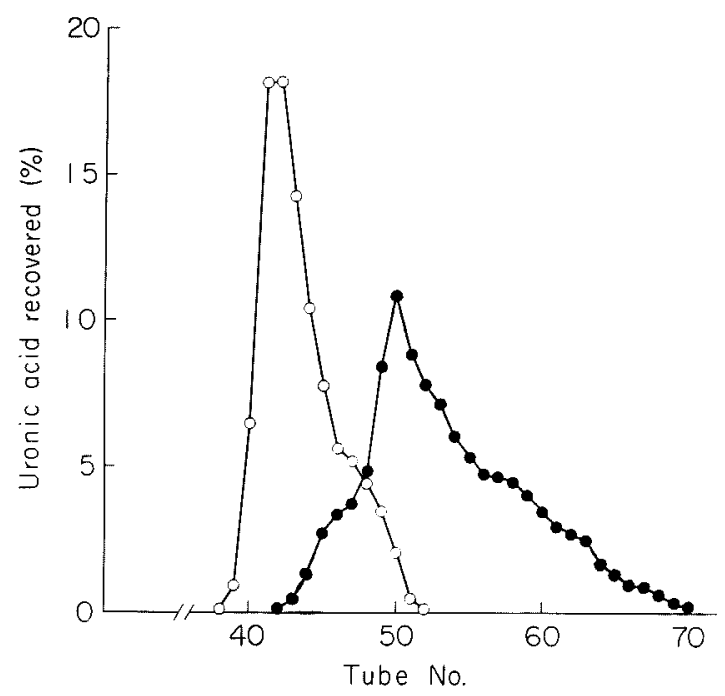

Fig. 1 .

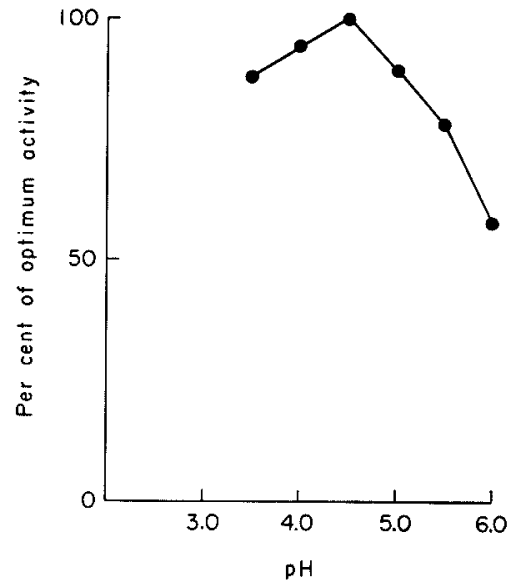

Fig. 2.

Fig. 1. Elution patterns of chondroitin-6-sulfate and hyaluronidase degraded chondroitin6-sulfate from Sephdex G-25 column $(190 \times 2 \mathrm{~cm}) .5 \mathrm{ml}$ fractions were collected. $0-0$, chondroitin-6-sulfate; -- $\bullet$ hyaluronidase degraded chondroitin-6-sulfate.

Fig. 2. pH activity profiles of $\mathbf{N}$-acetylgalactosamine-6-sulfate sulfatase in control liver. Activities were measured in a range of $0.6 \mathrm{M}$ Tris-acetate buffers between $\mathrm{pH} 3.5$ and 6.0 . 
TABLE 1. N-acetylgalactosamine-6-sulfate sulfatase activities in liver from two sisters with Morquio syndrome

\begin{tabular}{cccc}
\hline & $\begin{array}{c}\text { N-acetylgalactosamine- } \\
\text { 6-sulfate sulfatase } \\
\text { (nmoles inorganic sulfate/mg } \\
\text { protein/18 hr) }\end{array}$ & $\begin{array}{c}\beta \text {-D-galactosidase } \\
\text { (nmoles/mg protein/hr) }\end{array}$ & $\begin{array}{c}\text { N-acetyl- } \beta \text {-D- } \\
\text { glucosaminidase }\end{array}$ \\
\hline Morquio syndrome & 0 & 346 & 3302 \\
Elder sister & $2.2(4.7)^{*}$ & 369 & 3685 \\
Younger sister & 46.9 & 670 & 1834 \\
Control $(n=3)$ & $29.9-58.4$ & $308^{-1026}$ & $1409-230$ \\
Range & & & -230
\end{tabular}

not detected in liver obtained from the elder sister with classic Morquio syntrome and $4.7 \%$ of the control in liver from the younger sister (Table 1 ).

The excessive urinary excretion of KS and C-6-S in our two patients (Orii et al. 1973), and the accumulation of $\mathrm{KS}$ and $\mathrm{C}-6-\mathrm{S}$ in liver from the younger sister (Minami et al. 1979) could be explained by the markedly redured $\mathrm{N}$-acetylgalactosamine-6-sulfate sulfatase activity. $\beta$-D-Galactosidase activities in liver from Morquio syndrome were within normal range, differing from Hurler and Hunter syndromes (Kint et al. 1973). This difference suggest that the accumulation of dermatan sulfate or HS inhibits $\beta$-D-galactosidase activity, while the accumulation of $\mathrm{KS}$ may not inhibit the activity. $\mathrm{N}$-Acetyl- $\beta$-D-glucosaminidase activities in iver from Morquio syndrome were higher than those in control individuals.

\section{Acknowledgments}

We are grateful to Ms. M. Toyoda for valuable technical help.

\section{References}

1) Di Ferrante, N., Ginsberg, L.C., Donnelly, P.V. \& Di Ferrante, D.T. (1978) Deficiencies of glucosamine-6-sulfate or galactosamine-6-sulfate sulfatases are responsible for different mucopolysaccharidoses. Science, 199, 79-81.

2) Dische, Z. (1947) A new specific color reaction of hexuronic acids. $J$. biol. Chem., 107, $189-198$.

3) Dodgson, K.S. \& Price, R.G. (1962) A note on the determination of the ester sulphate content of sulphated polysaccharides. Biochem. $J, 84,106-110$.

4) Ginsberg, L.C., Donnelly, P.V., Di Ferrante, D.T., Di Ferrante, N. \& Caskey, C.T. (1978) N-acetylglucosamine-6-sulfate sulfatase in man: Deficiency of the enzyme in a new mucopolysaccharidosis. Pediat. Res., 12, 805-809.

5) Glössl, J. \& Kresse, H. (1978) A sensitive procedure for the diagnosis of N-acetylgalactosamine-6-sulfate sulfatase deficiency in classical Morquio's disease. Clin. chim. Acta, $88,111-119$.

6) Horwitz, A. \& Dorfman, A. (1978) The enzyme defect in Morquio's disease: The specificity of $\mathrm{N}$-acetylhexosamine sulfatases. Biochem. biophys. Res. Commun., 80, 819-825.

7) Kint, J.A., Dacremont, G., Carton, D., Orye, E. \& Gooft, C. (1973) Mucopolysaccharidosis. Secondarily induced abnormal distribution of lysosomal isoenzymes. Science, 181, 352-354. 
8) Koto, A., Howwitz, A.L., Suzuki, K., Tiffany, C.W.\& Suzuki, K. (1978) The Morquio syndrome: Neuropathology and biochemistry. Ann. Neurol., 4, 26-36.

9) Lowry, O.H., Rosenbrouch, N.J., Farr, A.L. \& Randhall, R.J. (1951) Protein measurement with the Folin phenol reagent. J. biol. Chem., 193, 265-275.

10) Matalon, R., Arbogast, B., Justice, P., Brant, I.K. \& Dorfman, A. (1974) Morquio's syndrome: Deficiency of a chondroitin sulfate $\mathrm{N}$-acetylhexosamine sulfate sulfatase. Biochem. biophys. Res. Commun., 61, 759-765.

11) Minami, R., Abo, K., Kudoh, T., Tsugawa, S., Oyanagi, K. \& Nakao, T. (1979) Identification of keratan sulfate in liver affected by Morquio syndrome. Clin. chim. Acta, 93, 207-213.

12) Orii, T., Minami, R., Takase, H. \& Nakao, T. (1973) Pattern of urinary acid mucopolysaccharide excretion in five patients with genetic mucopolysaccharidoses. Tohoku J. exp. Med., 110, 41-48.

13) Orii, T., Sukegawa, K., Minami, R., Matsuura, Y., Tsugawa, S., Horino, K., Maeda, E., Nakao, T.\& Kushida, H. (1976) Atypical Hurler syndrome without a-L-iduronidase deficiency. Tohoku J. exp. Med., 120, 113-123.

14) Singh, J., Di Ferrante, N., Niebes, P. \& Tavella, D. (1976) N-Acetylgalactosamine6-sulfate sulfatase in man. Absence of the enzyme in Morquio disease. J. clin. Invest., 57, 1036-1040.

15) Svennerholm, L. (1956) The determination of hexosamines with special reference to nervous tissue. Acta soc. med. upsalien., 61, 287-307. 